\title{
ÁGUA: DA LÓGICA DE MERCADO À EFETIVAÇÃO COMO DIREITO HUMANO. UMA LEITURA A PARTIR DO DIREITO INTERNACIONAL DOS DIREITOS HUMANOS
}

\author{
Sidney Cesar SilvaGuerra ${ }^{1}$ \\ Vinícius Pinto Moura ${ }^{2}$
}

\begin{abstract}
Resumo
Tratamos as recentes mudanças político-jurídicas acerca da água. Incialmente entendida como elemento abundante e livre, a visão sócio-política acerca dela vem sendo transformada. Passou a ser cada vez mais compreendida sob um viés econômico-racionalista, cujos reflexos são modelos de regulação e gestão sob a égide do mercado e a permanência de um quadro de crise e violações aos direitos humanos que lhe são conexos. No século XXI, há reações e uma sensível oposição a esse modelo, com a construção de mecanismos político-jurídicos de direito internacional, a fim de proteger e definir a água como direito humano. Objetivamos avaliar essa transição.
\end{abstract}

Palavras-chave: Água. Direito à água. Direitos Humanos. Direito Internacional. Direito Ambiental.

\section{WATER: FROM MARKET LOGIC TO EFFECTIVENESS AS A HUMAN RIGHT. A READING FROM INTERNATIONAL LAW HUMAN RIGHTS.}

\begin{abstract}
We deal with recent political-legal changes about water. Initially understood as an abundant and free element, the socio-political vision about it has been transformed. It has become increasingly understood under an economic-rationalist approach, whose reflexes are a regulation and management under the aegis of the market and the permanence of a crisis and human rights violations that are related to it. In the twenty-first century, there are reactions and a sensitive opposition to this model, with the construction of political-legal mechanisms of international law, in order to protect and define water as a human right. We aim to evaluate this transition.
\end{abstract}

Keywords: Water. Right to water. Human Rights. International Law. Environmental Law.

\footnotetext{
${ }^{1}$ Pós-Doutor - Universidade de Coimbra; Pós-Doutor - Universidade Federal do Rio de Janeiro. Professor Associado - Universidade Federal do Rio de Janeiro. Presidente do Instituto Brasileiro Pacificador. Líder do Grupo de Pesquisa em Direito Internacional - UFRJ. Advogado no Rio de Janeiro. Contato: sidneyguerra@terra.com.br

${ }^{2}$ Mestre em Geografia (UFRJ). Bacharel em Geografia (UFRJ). Integrante do Grupo de Pesquisa em Direito Internacional da Faculdade Nacional de Direito da Universidade Federal do Rio de Janeiro - FDN/UFRJ. Contato: regvinicius@gmail.com
} 


\section{INTRODUÇÃO}

As manchetes a seguir foram extraídas de diversos veículos nacionais e internacionais: "DF enfrenta racionamento na maior crise hídrica da história"3; " Dead Rivers, Closed Beaches': a water crisis on Long Island"4; "L'eau: marchandise ou bien commun?"5; "Deuda con los chicos: 3 de cada 10 no tienen agua potable en el Gran Buenos Aires" 6.

Um exame superficial das chamadas jornalísticas talvez permita, mesmo para um leigo, chegar a duas conclusões. Primeiro, o acesso à água se apresenta como um problema cada vez mais relevante. A segunda conclusão, talvez menos provável do que a primeira, é que o problema, a despeito de diferenças regionais e socioeconômicas, afeta ou afetará a todos.

Grosso modo, sob o escrutínio do senso comum, a questão hídrica pode ser definida como "falta d'água". No entanto, ela é mais complexa que isso, pois possui caráter político e se insere em um contexto de desordem ecológica (Porto Gonçalves, 2006, p. 41). O acesso genérico à água doce - em termos quantitativos e qualitativos, para diversos usos, em especial para a realização de necessidades básicas cotidianas - se apresenta, em diversos espaços ao redor do mundo, como algo conflitivo. E isto se explica graças a uma conjuntura de progressiva competição hídrica.

Aponta-se, em muitos casos, sob argumentação neomalthusiana ${ }^{7}$, apenas o aumento genérico do crescimento das demandas pela água, fruto do "desenfreado crescimento populacional", como o cerne da questão, associado a um discurso que naturaliza a escassez hídrica $^{8}$. Mas, há que sobrepesar àquela abordagem a ocorrência de profundas assimetrias

\footnotetext{
${ }^{3}$ Disponível em: <http://g1.globo.com/jornal-nacional/noticia/2017/02/df-enfrenta-racionamento-na-maior-crisehidrica-da-historia.html>. Acesso em: 17 abr. 2017.

${ }^{4}$ Disponível em: <https://www.nytimes.com/2017/05/08/nyregion/dead-rivers-closed-beaches-an-acute-watercrisis-on-long-island.html?_r=0>. Acesso em: 17 abr. 2017.

${ }^{5}$ Disponível em: <http://www.liberation.fr/evenements-libe/2017/01/04/l-eau-marchandise-ou-biencommun_1537677>. Acesso em: 17 abr. 2017.

${ }^{6}$ Disponível em: <https://www.clarin.com/sociedad/deuda-chicos-agua-potable-gba_0_rk-A2CTB.html>. Acessos em: 17 abr. 2017.

${ }^{7}$ A abordagem neomalthusiana do crescimento populacional revisita partes do pensamento de Thomas Malthus (1766-1834). Os neomalthusianos entendem que o crescimento populacional tem efeito no esgotamento dos recursos, com prejuízos sociais e econômicos. Uma vertente mais recente dessa escola, intitulada de econeomalthusiana, recomenda políticas de controle de natalidade a fim de evitar os efeitos e pressões sobre o meio ambiente. As duas principais críticas a esse conjunto de pensamentos são: 1- há uma tendência global em curso de redução do crescimento populacional, inclusive em alguns países periféricos/em desenvolvimento; 2- o modelo econômico predatório associado ao desenvolvimento de sociedades de consumo, sobretudo em países ricos. Dessa forma, o problema teria componentes mais complexos e próprios do sistema econômico em vigor.

${ }^{8}$ Vale destacar que, na verdade, conforme destaca Porto Gonçalves: "El nuevo discurso de la escasez nos dice ahora que el planeta tiene 3 de sus 4 partes de agua, 97 por ciento de esa área está cubierta por los océanos y mares y, por ser salada, no está disponible para consumo humano; del 3 por ciento restante, cerca de dos tercios
} 


\section{ÁGUA: DA LÓGICA DE MERCADO À EFETIVAÇÃO COMO DIREITO HUMANO. UMA LEITURA A PARTIR DO DIREITO INTERNACIONAL DOS DIREITOS HUMANOS}

entre grupos sociais e econômicos no que tange ao acesso à água, mesmo em países com abundância per capita do bem e com tendências de redução no crescimento populacional (Ribeiro, 2008, p. 24 e ss).

A crise da água é, em última instância, de natureza sócio-política. Ela é produto de uma imbricada e complexa conjugação de fatores. Está relacionada a um contexto mais amplo de crise ecológica e do desenvolvimento de uma sociedade de risco. Se no passado havia "uma percepção de que a água era um recurso ilimitado e talvez por essa razão a utilização do referido recurso tenha ocorrido de forma indiscriminada", na atualidade, o agravamento do quadro de crise impõe a urgente correção daquela visão míope (Guerra, 2013, p. 87).

É evidente que o aumento nas demandas é importante para explicar cenários de crise. Há, por outro lado, aspectos de relevância que sofisticam a argumentação sobre o problema. Podemos apontar, de modo não exaustivo, alguns deles: a) o contexto de mudanças climáticas e as incertezas quanto aos seus efeitos sobre os estoques das águas, sobre o deslocamento das massas de ar e sobre como isso pode e vai afetar a regularidade de chuvas em área de reservatórios e nascentes; b) o crescimento do consumo por alguns grupos sociais em detrimento de outros; c) as perdas e os desperdícios que são resultados tanto de ineficiências dos sistemas técnicos, públicos e privados, quanto de questões comportamentais dos diferentes tipos de usuários; d) a eficácia das políticas públicas de meio ambiente em seu aspecto protetivo de ecossistemas essenciais ao ciclo hidrológico.

Também tem importância na análise do contexto da crise da água o advento e relativa internacionalização - principalmente a partir das décadas de 1980 e 1990 - de um modelo econômico em que o Estado assume papel eminentemente regulador/fiscalizador dos bens e

están en estado sólido en los hielos y casquetes polares y por ello, también inaccesibles para consumo humano; de este modo, menos del uno por ciento del agua total del planeta sería potable, en un discurso de escasez elaborado de tal forma que, al final, el lector ya está con sed. Esa estadística, al intentar dar precisión científica al discurso de la escasez, comete errores básicos desde el propio punto de vista científico de donde procura obtener su legitimidad. Al final, el agua dulce que circula y que está disponible para consumo humano y además permite todas las formas de vida que el planeta conoce, es en gran parte, fruto de la evaporación de los mares y océanos cerca de $505.000 \mathrm{Km} 3$ - o sea, una capa de 1,4 metros de espesor que se evapora anualmente de los océanos y mares y que, aunque sean salados, no transmiten la sal en la evaporación. Se informa, además, que el $80 \%$ de esa agua evaporada de los océanos y mares se precipita sobre sus propias superficies. P.H. Gleyck (Gleyck, 1993) evalúa que de los $119.000 \mathrm{Km} 3$ de lluvias que caen sobre los continentes, $72.000 \mathrm{Km} 3$ se evaporan de los lagos, de las lagunas, de los ríos, de los suelos y de las plantas (evapotranspiración) y, así, 47.000 Km3 anualmente escurren de las tierras hacia el mar "de las cuales más de la mitad ocurre en Asia y en América del Sur, y una gran proporción, en un único río, el Amazonas, que lleva más de $6.000 \mathrm{Km} 3$ de agua por año" a los océanos (GEO 3: 150). Así, el agua disponible para la vida es, por lo menos desde el retroceso de la última glaciación entre 12.000 a 18.000 años atrás, la misma desde entonces hasta nuestros días, con pequeñas variaciones. Si no es mayor la cantidad de agua potable es porque, em verdad, mayor no puede ser, a no ser, como indicamos, por la regresión de los casquetes polares y de los glaciares fruto de los cambios climáticos planetarios producidos por causas complejas y, muy recientemente en términos de la historia del planeta, por la matriz energética fosilista post-revolución industrial" (Op. cit., p. 40). 
serviços públicos. São criados e se desenvolvem, desde então, modelos de gestão hídrica e de saneamento, bem como um arcabouço regulatório com grande ênfase em instrumentos de mercado que, de acordo com a ratio liberal, teriam a capacidade de racionalizar e diminuir as ineficiências anteriores. Exemplos disso são o desenvolvimento dos mercados de águas, o princípio poluidor-pagador, a cobrança pelo uso da água, as privatizações no setor de saneamento e outros mecanismos, incluindo alterações normativas, que deslocaram o sentido do termo "água" cada vez mais para a esfera econômica, sendo amplamente compreendido como sinônimo de uma commodity ${ }^{9}$.

Este modelo, todavia, se bastante replicado em diversos continentes, gerou, por outro lado, resultados discutíveis acerca da capacidade de promoção e desenvolvimento do acesso à água como direito de todos os seres humanos - sobretudo parcelas mais pobres e socialmente excluídas. Assim, não foi e não é incomum encontrar situações de escassez e grave afronta ao direito à água no cenário internacional ${ }^{10}$, mesmo em países ou regiões que, para usar o jargão econômico, "racionalizaram" o setor de águas ${ }^{11}$. E, justamente por esta razão, vem crescendo esforços em diversos setores da sociedade para que a água seja entendida como um elemento socioambiental e não como bem economicamente apreciável. Para além disso, há significativos ânimos e articulações no sentido de que, na esfera internacional, regional e, mesmo na brasileira, se possa buscar a proteção do direito à água nos diplomas internacionais de direitos humanos e também sua constitucionalização no rol dos direitos fundamentais.

A partir das considerações elaboradas até aqui, alguns questionamentos se colocam: a) como evoluiu a compreensão jurídica acerca da água?; b) quais os modelos regulatórios institucionais que foram depreendidos dessa evolução?; c) como vem se transformando, no plano internacional, a perspectiva e proteção jurídicas à água?;

De bem sujeito ao controle e dirigismo estatais até os anos 1970, passando pelo estágio de mercantilização das décadas seguintes, a água vem adentrando novo patamar. Passa

\footnotetext{
${ }^{9}$ Para uma caracterização detalhada deste aspecto, particularmente no que diz respeito às experiências de cobrança pelo uso da água, inclusive no Brasil, ver Moura (2006).

${ }^{10}$ O UN World Water Development Report, publicação da Agência da Organização das Nações Unidas para o Desenvolvimento dos Recursos Hídricos (UN Water), publicado em março de 2017, prevê que a demanda de água irá aumentar de forma significativa nas próximas décadas. Diz ainda que cerca 500 milhões de pessoas vivem em zonas onde o consumo supera, em uma proporção de 2 para 1, os recursos hídricos renováveis. E aponta que ao redor de dois terços da população mundial vive em zonas com escassez de água durante pelo menos 1 mês ao ano (Nações Unidas, 2017).

${ }^{11}$ Embora o setor de águas (water sector) seja considerado como o que cobre todos os usos das mesmas, incluindo as águas superficiais, subsuperficiais, e fontes recuperadas ou recicladas, o foco principal e corrente no emprego da expressão na literatura especializada vem expressando a comoditização da água. Assim, temas como alocação, finanças e gestão dos recursos hídricos são aqueles geralmente associados à expressão water sector (Saleth e Dinar, 2000, p. 176).
} 


\section{ÁGUA: DA LÓGICA DE MERCADO À EFETIVAÇÃO COMO DIREITO HUMANO. UMA LEITURA A PARTIR DO DIREITO INTERNACIONAL DOS DIREITOS HUMANOS}

a ser compreendida, ainda que de modo lento e gradual, como elemento socioambiental essencial à vida digna e à consecução de uma série de direitos inerentes à pessoa humana conexos - saúde, moradia, meio ambiente, por exemplo. O ápice desse processo se deu recentemente, com a Resolução 70/169 (2015) da Assembleia Geral das Nações Unidas, que reconheceu o direito humano à água.

O foco deste trabalho é, portanto, entender a transição de um modelo privatista para um humanista, avaliando os principais mecanismos de proteção internacional e reconhecimento jurídico da água na esfera dos direitos humanos ${ }^{12}$. A leitura de obras doutrinárias e o exame da legislação vigente compõem o tratamento qualitativo do trabalho, notadamente bibliográfico e documental. Vale ressaltar que, apesar de ser um trabalho no campo jurídico, em razão de tratar de tema complexo e que adentra variadas ciências, a pesquisa foi construída sobre alicerce multidisciplinar, destacando-se também referências oriundas das ciências ambientais e dos estudos da economia institucional, voltadas para a melhor caracterização e compreensão da questão hídrica.

\section{MUDANÇAS NA VALORAÇÃO/CONCEPÇÃo POLÍTICO-JURÍDICA DA ÁGUA E SEUS EFEITOS NA REGULAÇÃO}

Ao longo das últimas décadas é possível verificar uma mudança em como o Direito enxerga a água. As concepções sobre as águas doces, superficiais e subsuperficiais, passaram por transformações que alteraram as formas de regulação e gestão desse bem ${ }^{13}$. Vale ressaltar aspecto central: durante boa parte do tempo, inclusive atualmente, predomina a visão que instrumentaliza, enfatiza e superdimensiona a água como mero elemento do desenvolvimento econômico e não como direito humano. A consequência disso foi a construção de artifícios

\footnotetext{
${ }^{12}$ GUERRA, Sidney. Direito internacional dos direitos humanos. 2. ed. São Paulo: Saraiva, 2015, p. 79: "O direito internacional dos direitos humanos tem por objeto o estudo do conjunto de regras jurídicas internacionais (convencionais ou consuetudinárias) que reconhecem aos indivíduos, sem discriminação, direitos e liberdades fundamentais que assegurem a dignidade da pessoa humana e que consagrem as respectivas garantias desses direitos"

${ }^{13}$ Uma ideia mais ampla de regulação representa um conjunto de regras e ações estabelecidas pelo Estado ou quaisquer outras formas de autoridade, legítimas ou ilegítimas, públicas ou privadas, visando imprimir algum tipo de organização à sociedade. Isso faz, até certo ponto, uma importante referência à normatividade e cogência jurídicas, contudo, em função de uma perspectiva valorativa da água como recurso escasso e sujeito ao cálculo econômico, a nomenclatura regulação tem sido utilizada, em especial nas ciências econômicas, para expressar um processo de organização de setores das esferas social e econômica que teriam certa propensão à desordem, ou seja, que gerariam resultados sub-ótimos em caso de não-regulação ou inobservância dos interesses públicos (Clarke, 2000). Pelo que se depreende, tal visão não deixa de se refletir em uma ordem jurídica correspondente, na produção de um sistema normativo.
} 
jurídico-institucionais para intervenção ora do Estado, ora do mercado sobre o regime das águas. Porém, dadas as limitações dessa concepção economicista acerca da água, há, em curso, uma sensível migração para entendimento da água como elemento que possui ligação imanente com a dignidade da pessoa humana.

De modo resumido, apontamos três momentos na concepção jurídica e regulatória da água. A primeira fase coincide com o alastramento do processo de industrialização entre o final do século XIX e vai, em maior ou menor medida, até os anos 1970, quando a profunda crise do sistema capitalista impõe importante inflexão. Até esse momento, as águas eram vistas como bem livre e natural, porém, claramente à disposição de um projeto modernizador de matriz industrial. Logo, seus usos e os desenhos institucionais que incidiam sobre a gestão desse bem privilegiaram modelo centralizador e com forte controle estatal, em que, não raro, eram beneficiados alguns setores econômicos, notadamente o industrial e o energético. Portanto, o controle estratégico da água pelo Estado esteve na base da aplicação da regulação na maioria dos países ocidentais até os anos 1970, predominando o desenho de um modelo de gestão pública que primava pela nacionalização.

As experiências europeia e norte-americana, formaram a base dos modelos mais ou menos replicados em outras partes do mundo. Na Europa, por exemplo, esse processo de nacionalização ganhou força após a $2^{\mathrm{a}}$ guerra mundial, tendo como objetivos alcançar a eficiência no uso e alocação dos recursos - inclusive da água - por meio do controle de preços, da quebra de monopólios privados mediante introdução de concorrentes públicos, da obtenção de economias de escala, da reestruturação e racionalização do setor industrial, e, por fim, de investimentos intensivos em setores de produção de bens ou serviços considerados estratégicos, por exemplo. Além disso, visava a democracia econômica através da distribuição dos recursos, com redução de preços de bens e serviços produzidos e estímulos ao desenvolvimento regional, no sentido de reduzir desigualdades. Dito de outro modo, a regulação europeia era fruto do contexto do pós-guerra, em que objetivos macroeconômicos de recuperação e crescimento moldaram o controle do desenvolvimento em razão da propriedade pública e planificação econômica (Mattos, 2002; Moura, 2002).

Já nos EUA, apesar dos objetivos serem mais ou menos parecidos no que diz respeito à regulação da economia, entendendo a água também sob a perspectiva de recurso para o desenvolvimento, são estabelecidas estratégias que diferem um pouco das europeias. Foi conferido no modelo norte-americano maior peso à criação de agências regulatórias 


\section{ÁGUA: DA LÓGICA DE MERCADO À EFETIVAÇÃO COMO DIREITO HUMANO. UMA LEITURA A PARTIR DO DIREITO INTERNACIONAL DOS DIREITOS HUMANOS}

independentes ${ }^{14}$. A experiência norte-americana por meio de agências reguladoras passou a ter grande importância na década de 1930, na esteira dos desdobramentos da grave crise econômica de fins da década anterior. Todavia, cabe destacar que, a partir dos anos 1960, até mais ou menos os anos 1980, uma abordagem conhecida como New Social Regulation passa a ser igualmente relevante. Se, em uma primeira etapa, a concernência era o controle do poder monopolista e da concorrência predatória, no período subsequente as preocupações orbitavam - ao menos no plano teórico - em corrigir problemas de assimetrias e seus efeitos sobre os consumidores, em melhorar os resultados das intervenções regulatórias e, com necessária menção, em proteger o meio ambiente - que passa a figurar de maneira mais enunciada como objeto da regulação econômica e social.

A severa crise econômica do começo dos anos 1970 se alastrou pelo decênio seguinte e teve fortes efeitos sobre aquele quadro. $\mathrm{O}$ primeiro deles foi o questionamento sobre o papel do Estado na regulação social e econômica e, portanto na condução da administração pública. De acordo com a abordagem neoliberal que passa a fazer sucesso àquele instante, as ineficiências das estruturas jurídico-institucionais eram indicadas, sendo exemplos de um malfadado intervencionismo estatal, cujas distorções, desperdício de recursos públicos e pouca transparência eram alguns de seus problemas. A Escola de Chicago, principal expoente da ótica neoliberal, propunha a reformulação da regulação, das instituições e, por conseguinte, das correspondentes regras jurídicas na condução a uma ordem econômico-social menos burocrática e com menor presença do Estado. Este, por sua vez, deveria assumir um papel notadamente fiscalizador, contribuindo para um ambiente em que os agentes privados e as forças de mercado alavancariam o desenvolvimento econômico.

O advento dessa visão liberalizante orientou as práticas de gestão pública ao redor do mundo. As privatizações, as políticas de reforma do aparelho estatal e as correspondentes mudanças institucionais e jurídicas dão a tônica desse contexto ${ }^{15}$. Nesse sentido, as águas

${ }^{14}$ Conhecidas como Regulatory Agencies ou Independent Regulatory Comissions. Estas se multiplicam e adquirem força após o New Deal's National Recovery Act (1933), figurando como mecanismos para intervenção do Estado sobre a economia (McCraw, 1984).

15 À primeira vista, as mudanças regulatórias nos Estados Unidos e na Europa seguiram dois caminhos: a saída do Estado de atividades produtivas via privatização; a criação de novas instituições e normas regulatórias. Na verdade, como as mudanças naqueles espaços influenciaram as práticas em diversos países, podemos dizer que poucos adotaram apenas uma dessas alternativas. O mais comum, ao se avaliar o panorama internacional, é a filiação às duas tendências (Majone, 1990; Moran e Prosser, 1994). A despeito das peculiaridades das reformas regulatórias, elas exprimiram, em maior ou menor medida, a liberalização dos mercados, sob argumento da defesa da concorrência. Há que ressalvar, entretanto, que reformas regulatórias podem consentir a legitimação de grandes concentrações econômicas, acarretando mesmo a existência de monopólios que seriam elementos essenciais ao desenvolvimento de setores alguns da economia. 
continuam a ser instrumentalizadas como recurso. A diferença, no entanto, é na concepção sobre quais devem ser os instrumentos e políticas de gestão que permitam uma maior eficiência no setor. E também sobre quais agentes terão espaço nos novos modelos institucionais que serão delineados. Mais ainda: apesar da água ser entendida como recurso natural, ela passa a ser considerada cada vez mais a partir de valores econômicos (escassez, finitude, preço, alocação, custo de oportunidade, commodity, recurso dotado de valor econômico) que constituem a nova semântica de referência institucional na maioria dos países do mundo. A água, é, cada vez mais compreendida como recurso econômico e, portanto, apreciável e alienável e sai da esfera de decisões público-estatal para entrar, cada vez mais, na órbita do mercado (García, 2008, p. 57).

Adquire espaço uma concepção normativa da água que é reflexo de sua economicização. Assim, vemos uma transformação dupla de ordem prática: 1- surgem novas regras jurídicas que reformam os desenhos institucionais que regulam as águas e o serviço de saneamento básico; 2- as novas regras promovem um amplo processo de privatizações e incorporação de estratégias mercantis para racionalização dos usos conforme as leis da oferta e demanda. Um breve exame da experiência internacional na área mostra que a Europa e os EUA também se lançaram primeiro nesse processo de reformas referentes à água. Tanto em um caso como no outro, o crescimento da demanda por água foi o fator decisivo (Hobbs, 1997). Houve a permissão legal para a criação de associações de usuários com o objetivo de promoverem a defesa de interesses comuns (Simpson e Ringskog, 1997; Barraqué, 1998).

Nos EUA ocorreram diversas regulamentações que acarretaram no surgimento de diversos tipos de agências independentes, federais, interestaduais e também na escala regional ou local. A superposição de competências operou para a aprovação do Water Quality Act, em 1965, lei federal para a gestão das águas; já em 1972, foi aprovada o Clean Water Act referente ao controle da poluição das águas, mais alterada (Carrera-Fernandez e Garrido, 2002). Já na Europa, foram criadas leis reformadoras dos sistemas, com previsão de mecanismos de racionalização econômica - como foi no caso francês. $\mathrm{O}$ avanço no processo de integração comunitária levou à aprovação da Diretiva Europeia para a Água, em 2000. E, vale salientar ainda, que há grandes grupos econômicos que controlam parcialmente os serviços de saneamento e oferta de água, em níveis variados, tanto nos EUA como na Comunidade Europeia (Barraqué, 2014). 
No restante do mundo, as mudanças jurídico-institucionais na regulação da água e do saneamento igualmente conduziram a uma orientação que busca racionalização e mercantilização, apesar dos modelos variarem bastante. Chama atenção o fato de que, na maioria dos países - com algumas poucas exceções, como nos EUA e no Chile - a água é um bem público de uso comum, não suscetível ao direito de propriedade. Como falar então em mercantilização da água? A resposta para essa aparente contradição está no fato de que, a principal forma de acesso à água se dá, especialmente em áreas urbanas, por meio de serviços de abastecimento e saneamento que vem sendo privatizados e controlados por grandes grupos empresariais mediante diferentes modalidades contratuais. Barlow e Clarke (2004) apontam cerca de dez grandes corporações, atuando hoje nesse lucrativo mercado ${ }^{16}$ que se internacionalizou e financeirizou.

Os efeitos dessas políticas e novos marcos regulatórios, no entanto, não foram capazes de garantir a resolução ou minimização dos problemas de acesso e a efetivação de direitos relacionados ao próprio direito à água. Em alguns casos, houve fortes reações populares contra as privatizações, como é o caso da guerra da água, na Bolívia. Há ainda, movimentos no sentido de empreender a remunicipalização dos serviços de água e saneamento, motivados pelo crescimento brutal de tarifas (e.g. de Berlim e Kuala Lumpur), desempenho medíocre das empresas privadas (e.g. de Dar es Salaam, Accra, Maputo), subinvestimento (e.g. Berlim, Buenos Aires), falta de transparência financeira (e.g. Grenoble, Paris, Berlim), deficiente qualidade do serviço (e.g. Atlanta, Indianápolis), dentre outros motivos (Satoko et. al., 2015).

As reações ao modelo economicista e privatista acerca da água são frutos de demandas coletivas de diversos grupos da sociedade, sobretudo aqueles que se inserem em contextos de maior vulnerabilidade. Eles buscam, mesmo que de modo inconsciente, o reconhecimento do direito humano à água. A constitucionalização do direito à natureza e à água em algumas Cartas Magnas latino-americanas, a evolução desse direito nos sistemas normativos internacional, interamericano e europeu, e, por fim, a atuação judicial podem, progressivamente, viabilizar o alcance de sua proteção. Isso representa, a nosso ver, o terceiro e novíssimo momento na evolução da concepção jurídica e regulatória da água. Sua valoração como commodity passa a ser questionada, bem como os limites dos poderes privados frente a

\footnotetext{
${ }^{16}$ Suez, Vivendi e Bouygues-SAUR, todas da França; RWE-Thames Water, alemã; Bechtel-United Utilities, American Works Company e Enron-Azurix, dos EUA; por fim, as britânicas Severn Trent, Anglan Water e Kelda Group.
} 
ela, vindo a ser juridicamente direito humano, conforme abordaremos mais detalhadamente adiante.

\section{A ÁGUA COMO DIREITO HUMANO: UMA LEITURA A PARTIR DO DIREITO INTERNACIONAL}

Antes de avaliarmos o estado da arte que concerne a inserção da água no conjunto do sistema internacional que protege os direitos humanos, é necessário e importante precisar o fundamento que alicerça aquele elemento como direito.

Não é possível nos dedicarmos a essa tarefa sem lembrar que a água é essencial à vida, condição básica para sua manutenção e plenitude, além de elemento essencial para estruturação das atividades humanas que ensejam o desenvolvimento social, cultural e econômico, tais como a agricultura e a indústria, por exemplo.

Do ponto de vista biológico, o direito à água tem relevância essencial. A negligência no acesso a este elemento, materializada em padrões qualitativos e quantitativos inadequados e inaceitáveis, pode exercer fortes impactos sobre a qualidade de vida e mesmo as chances de sobrevivência de um ser humano. A falta ou mesmo a incompletude no saneamento básico, e também de sistemas mais robustos e eficientes para o tratamento das águas, manifestam-se na contaminação e na correspondente prevalência de doenças de veiculação hídrica, cujo impacto é enorme nas estruturas sociais e econômicas de diversos países ${ }^{17}$.

$\mathrm{O}$ acesso às águas sanas, limpas, em quantidade compatível com as necessidades humanas diárias representa, portanto, um parâmetro do mínimo existencial que está na base definidora da dignidade humana. A água constitui, sem embargo, um meio do qual não se pode dispor, sob pena de se colocar em risco a própria condição humana. Deveria provir daí um sistema de gestão das águas que tivesse seus alicerces construídos sobre o interesse geral coletivo, com participação ativa das comunidades. Mais além: a água deveria alçar, progressivamente, o status de um autêntico direito humano pleno, reconhecido e protegido na ordem jurídica internacional (Shiva, 2003, p. 33-35).

\footnotetext{
${ }^{17}$ Dados de monitoramento dos Objetivos de Desenvolvimento Sustentável da Organização das Nações Unidas (ODS/Onu) mostram que cerca de 700 milhões de pessoas no mundo não têm acesso a água segura. Cerca de 2,5 bilhões não têm saneamento adequado e quase 1 bilhão de pessoas defecam a céu aberto. O reflexo disso é que cerca de $80 \%$ das doenças em países em desenvolvimento são causadas por ingestão de água não potável e saneamento precário, incluindo instalações de saneamento inadequadas. Disponível em: <https://nacoesunidas.org> Acesso em 22 de abril de 2017.
} 
A água tem, graças a sua indispensabilidade à vida, uma capacidade transversal que se manifesta em outras categorias de direitos humanos. Isto quer dizer que o direito à água está estritamente ligado a outros direitos, sendo um componente que os atravessa, lhes conferindo, em maior ou menor medida, consistência e tangibilidade. Dito de outra maneira: o direito (de acesso) a água se constitui necessário para que outros direitos se realizem de forma integral. E é assim como o direito à vida digna, protegido na esfera internacional, em que se obriga o Estado sob o prisma duplo: não ameaçar a dignidade e a vida propriamente dita; buscar a realização de medidas positivas, prestacionais, para incremento da dignidade humana.

Adotando uma perspectiva ampla do direito à vida, o acesso à água é um fator primordial para a diminuição de algumas ameaças àquela, tais como o meio ambiente degradado, condições precárias de moradia e saneamento, epidemias, dentre outros. Fica patente que o direito à água tem reflexos diretos sobre outros direitos, que podem incrementar ou não as expectativas de vida e a própria existência digna de diversos grupos sociais. Há, evidentemente, interdependência e indivisibilidade entre o direito à água e outros direitos humanos que estão estabelecidos no rol normativo - direito à moradia digna, à saúde, à propriedade, ao meio ambiente saudável, à cultura, ao desenvolvimento (Garcia, 2008, p. 25$50)$.

O reconhecimento do direito à água enquanto direito humano tem função educativa e informadora. Permite - no plano estatal, pois na maioria dos países as águas são estritamente res publica - que se dê maior peso para a definição de políticas de governança da água, que contribuam para diminuição de conflitos de usos, escassez e degradação das condições ambientais. Ao mesmo tempo, a distinção tem função de salvaguardar os direitos de grupos sociais mais vulneráveis das próprias assimetrias geradas pelo Estado ou toleradas por ele (Quirico e Boumghar, 2016, p. 39-50). Logo, até em países em que há a figura das águas particulares ou privadas, como mencionamos anteriormente, o Estado não se desobriga de limitar o direito de propriedade face aos direitos humanos da pessoa.

$\mathrm{O}$ direito natural de acesso à água demanda marcos normativos que garantam "su vigência ya no sólo frente a los poderes públicos tradicionales, sino sobre todo frente a los poderes privados involucrados em la explotación y manejo de este recurso vital" (García, p. 20). Representa, portanto, um limite à perspectiva que se tornou dominante que valora a água, primordialmente e muitas vezes estritamente, como recurso escasso, dotado de economicidade, como antes apontamos. 
O fundamento do direito à água como um direito humano advém, então, dos aspectos já mencionados, referentes à indisponibilidade de tal bem à vida digna e seu vínculo com a realização de outros direitos. Tal fundamento está adstrito à escassez, compreendida em sua complexidade como expressão tanto da dinâmica ecológica, quanto das formas de apropriação social. A escassez é resultado dessa conjugação de numerosos elementos, mas os contornos sociais adquirem substancial relevância para explicação do problema, pois, mesmo em regiões geográficas com abundância hídrica, há flagrantes desequilíbrios e assimetrias no acesso à água. A escassez da água é socialmente produzida, variando espacial e temporalmente, mas se dá a partir da constatação de evidente desfavor na acessibilidade ao bem - em quantidade, qualidade ou considerando ambas.

O conteúdo do direito à água tem que levar em consideração a escassez, as limitações de acesso e como isso restringe a efetivação de outros direitos humanos. A noção de adequabilidade é importante, mesmo que variem a escassez e, de modo correlato, as condições mínimas de acesso. Isso coloca a questão de como definir o conteúdo material, concreto. De outro modo: qual é a quantidade de água que um ser humano deve dispor, necessária para consecução de parte substancial do mínimo existencial ${ }^{18}$ Nesse sentido, organizações internacionais como a Organização Mundial de Saúde (OMS) e a ONU propõem entre 100 e 110 litros diários de água como o standard mínimo para um ser humano saciar a sede, ter higiene adequada e preparar os alimentos ${ }^{19}$.

Apesar disso, a valoração da água como direito humano é algo relativamente recente e, por isso mesmo, a discussão acerca dos standards não está esgotada. Até mesmo porque as

\footnotetext{
${ }^{18}$ É evidente que o mínimo aceitável também tem relação com parâmetros de qualidade das águas, que são indicados pela OMS em diversas publicações técnicas como OMS (2010; 2011; 2015) (2010). Disponíveis em <http://www.who.int/water_sanitation_health/publications/en/>. Acesso em 06 de maio de 2017. Mas vale salientar que as normas ambientais internas de cada país definem os parâmetros técnicos qualitativos que são aceitáveis. No Brasil, a Resolução 357/2005 do Conselho Nacional de Meio Ambiente estabelece alguns parâmetros no que se refere à qualidade da água para uso doméstico e industrial. A Sabesp, companhia de saneamento de São Paulo, aponta parâmetros que devem ser regularmente monitorados para fins de controle da qualidade, tais como nível de cloro e cloroamoniação, turbidez, cor, pH, coliformes, flúor. <http://site.sabesp.com.br/site/interna/Default.aspx?secaoId=40> Acesso em 06 de maio de 2017.

19 Algumas comparações: de acordo com a organização não-governamental Water Footprint Network, são necessários 10 litros para a produção de uma folha de papel, 300 mil litros são empregados na fabricação de uma tonelada de aço e 109 litros para produzir um copo de vidro; já a fabricação de um automóvel absorve 400 mil litros de água, em média, e uma barra de chocolate consome 1.700 litros; a Fundação das Nações Unidas para Alimentação e Agricultura (FAO) estima sendo necessários de mil a três mil litros de água para a produção de 1 $\mathrm{kg}$ de arroz e de 12 mil a 21 mil litros de água para a produção de $1 \mathrm{~kg}$ de carne bovina; por fim, 107 litros de água é o consumo per capita/dia na Dinamarca, enquanto que a média brasileira é de 166,3 litros per capita/dia e a da Grande São Paulo giraria em torno de 175 litros por dia. No estado do Rio de Janeiro o índice, em 2013, foi de 253,1 litros por dia. Fontes: <http://waterfootprint.org/en/> Acesso em 06 de maio de 2017; <http://www.fao.org> Acesso em 06 de maio de 2017; <http://www.snis.gov.br/> Acesso em 06 de maio de 2017.
} 


\section{ÁGUA: DA LÓGICA DE MERCADO À EFETIVAÇÃO COMO DIREITO HUMANO. UMA LEITURA A PARTIR DO DIREITO INTERNACIONAL DOS DIREITOS HUMANOS}

necessidades humanas são variáveis no tempo e no espaço, o conteúdo material pode ser mais elastificado e deve levar em conta uma diversidade complexa de dados. No entanto, as obrigações dos Estados na efetivação desse direito e daqueles que lhe são correlatos não podem ter caráter regressivo, sob pena de representar involução e ineficácia social.

A preocupação com a água, sua preservação e sua proteção jurídica como um direito humano aparecem no sistema internacional muito recentemente. Pode-se afirmar que sua origem está inserida em um contexto mais amplo, de crise do sistema capitalista entre os as décadas de 1960 e 1970, em que ocorreram mudanças nos mecanismos de regulação que já aludimos. Elas se estenderam a diversos campos, introduzindo alguns que não apresentavam um sistema normativo consolidado, como o do meio ambiente. Tal fato revela que a crise foi de ordem produtiva, financeira e energética, mas também entendida pela sociedade como crise ambiental. E é nesse contexto que foi realizada a $1^{\mathrm{a}}$ Conferência Internacional sobre Meio Ambiente e Desenvolvimento, em 1972, pelas Nações Unidas.

O modelo econômico vigente passa a ser questionado graças aos limites que ele impõe à sustentabilidade ambiental - presente e futura. Também são denunciados os reflexos que a questão ambiental tem sobre o sistema econômico e o desenvolvimento das nações, bem como os impactos sobre a saúde pública e a qualidade de vida dos seres humanos. Mais ainda, a Conferência de 1972 afirma a importância do meio ambiente para ao gozo dos direitos humanos $^{20}$. E, na esteira desse movimento, a sociedade internacional passa a organizar conferências, encontros e fóruns para a discussão temática e detalhada do meio ambiente e de sua proteção. O reflexo disso é a construção de um sistema normativo internacional (tratados, resoluções, convenções) que busca proteger e compatibilizar as necessidades econômicas e a preservação e o próprio direito ao meio ambiente.

É nesse contexto que o Direito Internacional Ambiental ganha corpo e vulto como campo instrumental, recomendando e apresentando obrigações aos Estados, permitindo a sensibilização de diversos países para a causa ambiental e culminando na constitucionalização do meio ambiente e na construção de diversos regramentos infraconstitucionais ${ }^{21}$.

A água propriamente dita, como tema relativamente autônomo, surge no debate de discussão internacional na Conferência de Mar del Plata, em 1977. A Declaração que resultou do encontro apontou um entendimento da água como bem público de direito a todos os

\footnotetext{
${ }^{20}$ GUERRA, Sidney. Direito internacional ambiental. Rio de Janeiro: Freitas Bastos, 2006.

${ }^{21}$ GUERRA, Sidney. Curso de Direito Ambiental. 2. ed. São Paulo: Atlas, 2014.
} 
indivíduos: "All peoples, whatever their stage of development and their social and economic conditions, have the right to have access to drinking water in quantities and of a quality equal to their basic needs" (Nações Unidas, 1977, p. 66). Da mesma forma, a Declaração fez um chamamento aos Estados para que eles realizassem avaliações nacionais de suas águas e desenvolvessem planos e políticas para a satisfação das necessidades básicas nesse campo. Por fim, se estabeleceu ainda a década de 1980 como o período em que todas as pessoas deveriam ter acesso à água potável, segura e suficiente (Década Internacional da Água Potável e Saneamento Ambiental).

Já em 1992, em Dublin, foi realizada a Conferência Internacional sobre Água e Meio Ambiente. Em seu âmbito se reconhece a ameaça que representa a escassez e as formas abusivas no uso da água para o alcance do desenvolvimento sustentável, bem como para a proteção ambiental, dos ecossistemas, para o desenvolvimento econômico, segurança alimentar, saúde e bem-estar dos seres humanos (Nações Unidas, 1992). A conferência também resultou em uma declaração final que considerava, ainda que imprecisamente, a necessidade de se aperfeiçoar a gestão das águas e reconhecer o acesso às mesmas como um direito de todo ser humano. Mas ela aponta uma guinada para um enfoque mais econômico da gestão dos recursos hídricos ${ }^{22}$.

No mesmo ano de 1992, foi realizada no Rio de Janeiro, a Conferência das Nações Unidas sobre Meio Ambiente e Desenvolvimento, que ficou conhecida como Eco 92 e constituiu um dos principais eventos realizados sobre a matéria. Como resultado dos esforços da sociedade internacional em estabelecer uma aliança para a cooperação estatal para preservar o meio ambiente, o encontro resultou na Declaração do Rio sobre Meio Ambiente e Desenvolvimento. Nele são definidos alguns princípios, dentre os quais se destaca: os seres humanos constituem o centro das preocupações relacionadas ao desenvolvimento sustentável e tem direito a uma vida saudável e produtiva, em harmonia com a natureza (Nações Unidas, 1992b). Percebe-se, mais uma vez, o reforço no entendimento do meio ambiente como um direito em si, conectado ao direito à vida.

\footnotetext{
22 Os princípios apontados pela Declaração de Dublin para uma nova gestão das águas, que reforçam a concepção da água como recurso econômico, são os seguintes: "Principle $\mathrm{n}^{\circ}$. 1 - Fresh water is a finite and vulnerable resource, essential to sustain life, development and the environment; Principle $n^{\circ}$. 2 - Water development and management should be based on a participatory approach, involving users, planners and policy-makers at all levels; Principle $\mathrm{n}^{\circ} .3$ - Women play a central part in the provision, management and safeguarding of water; Principle $n^{\circ} .4$ - Water has an economic value in all its competing uses and should be recognized as an economic good" (Op. cit.).
} 


\section{ÁGUA: DA LÓGICA DE MERCADO À EFETIVAÇÃO COMO DIREITO HUMANO. UMA LEITURA A PARTIR DO DIREITO INTERNACIONAL DOS DIREITOS HUMANOS}

A Eco $92^{23}$, conhecida também como Cúpula da Terra, resultou ainda em um documento chamado Agenda 21. Ela "pode ser definida como um instrumento de planejamento para a construção de sociedades sustentáveis, em diferentes bases geográficas, que concilia métodos de proteção ambiental, justiça social e eficiência econômica" ${ }^{24}$. No que tange à proteção e desenvolvimento sustentável das águas doces, a Agenda 21, reserva um capítulo inteiro - capítulo 18 - em que se destacam diretrizes para o manejo, recomendações para o fortalecimento institucional das políticas públicas estatais que combatam a escassez, dentre outros aspectos. Mas, não há apontamentos diretos no documento que indiquem, de modo expresso, a água como direito humano. O que temos apenas é um reconhecimento tímido da água como necessária em todos os aspectos da vida (Nações Unidas, 1992c).

Ainda no plano da mobilização internacional e da progressiva instrumentalização da proteção à água, é necessário fazer menção à Declaração do Milênio. Ela foi resultado da Cúpula do Milênio das Nações Unidas realizada no ano 2000, na cidade de Nova Iorque, em que tivemos o estabelecimento de objetivos de desenvolvimento, conhecidos como Objetivos do Milênio $(\mathrm{ODM})^{25}$. Eles sintetizavam os propósitos a serem alcançados no novo milênio que se iniciava, através da cooperação global. No que concerne às águas a Declaração assinala a necessidade de por fim à exploração não-sustentável das mesmas, bem como de desenvolver estratégias que ordenem os usos dos recursos hídricos em diferentes níveis, promovendo o acesso equitativo e um abastecimento adequado. Já no plano dos ODM tivemos como desdobramento a elaboração de 18 metas. A meta número 10, estabeleceu expressamente o intento de reduzir até a metade, para o ano de 2015, o percentual de pessoas que careciam de acesso à água potável e a serviços de saneamento ${ }^{26}$.

\footnotetext{
${ }^{23}$ Vale salientar que a Eco 92 também teve como resultado a criação da Comissão de Desenvolvimento Sustentável das Nações Unidas (CDS), que foi estabelecida em 1993 como um elemento da estrutura do Conselho Econômico e Social das Nações Unidas (Ecosoc). García destaca acerca da CDS: "Desde entonces, la Comissión há celebrado numerosas reuniones y debates, algunos de ellos precisamente sobre questiones relacionadas com el agua" (Op cit., p. 153). A mesma autora ainda aponta que: "Lo certo es que Conferencia del Río tampoco supuso grandes avances em el panorama de la gestión mundial de los recursos hídricos. De hecho, em certo sentido, 'sirvió para instaurar um nuevo paradigma de explotación que, bajo la pantalla del desarrollo sostenible, quiere incorporar em la cadena de reproducción del capital los últimos bienes comunes del planeta' (Rosenberger, 2003: 78-79)" (Ibidem).

24 Disponível em: <http://www.mma.gov.br/responsabilidade-socioambiental/agenda-21/agenda-21-global> Acesso em: 08 mai. 2017.

${ }^{25}$ Os ODM são os seguintes: erradicar a pobreza e a fome; atingir o ensino primário universal; promover a igualdade entre os sexos e a autonomia das mulheres; reduzir a mortalidade da infância; melhorar a saúde materna; combater o HIV/Aids, a malária e outras doenças; garantir a sustentabilidade ambiental; estabelecer uma parceria mundial para o desenvolvimento.

${ }^{26}$ Em 2015 a Onu lançou o Relatório dos Objetivos de Desenvolvimento do Milênio 2015, em que assinalou avanços em vários dos objetivos. Sobre as águas vale destacar que o relatório aponta os seguintes dados: "In 2015, 91 per cent of the global population is using an improved drinking water source, compared to 76 per cent in 1990; Of the 2.6 billion people who have gained access to improved drinking water since 1990, 1.9 billion
} 
Outro documento importante é a declaração final da Conferência das Nações Unidas sobre Desenvolvimento Sustentável - 'Rio+20', realizada no Rio de Janeiro em 2012, intitulada The Future We Want. Os Estados reconhecem a necessidade de incluir o desenvolvimento sustentável em todos os níveis, integrando aspectos econômicos, sociais e ambientais e reconhecendo as suas interligações, de modo a alcançar um desenvolvimento sustentável em todas as suas dimensões ${ }^{27}$ (Nações Unidas, 2012, p. 1). Além disso, se reafirma o compromisso internacional com a busca da universalização do acesso à água e ao saneamento. Mais longe ainda, o documento aponta para o entendimento da água e do saneamento como um direito humano e para a necessidade de os Estados realizarem esforços contínuos no aperfeiçoamento de seus sistemas de gestão (Nações Unidas, 2012, p. 23).

Na verdade, a orientação do documento final da 'Rio+20', foi no sentido de reafirmar o câmbio importante que vinha ocorrendo na valoração da água, que passou a ser admitida expressamente como direito humano nos instrumentos internacionais em 2010 e, depois, de forma mais extensiva, em 2015, conforme veremos adiante. Antes disso, no entanto, a água enquanto direito humano, e em uma perspectiva positiva, não era assim distinguida nos instrumentos internacionais. Nem a Declaração Universal dos Direitos Humanos de 1948 (DUDH), tampouco os Pactos Internacionais sobre Direitos Econômicos, Sociais e Culturais (PIDESC), e sobre Direitos Culturais e Políticos (PIDCP), ambos de 1966, colocaram o direito humano à água de forma explícita em seus textos. É só a partir de um progressivo, mas lento, processo político de perfilhamento da comunidade internacional que a água é estruturada como direito humano.

É curioso que tal processo tenha se acelerado, se assim podemos dizer, a partir dos anos 2000, quando, em maior ou menor medida, é possível perceber ainda a prevalência da visão privatista e economicista acerca da água. Todavia, vale lembrar que é também no

gained access to piped drinking water on premises. Over half of the global population (58 per cent) now enjoys this higher level of service; Globally, 147 countries have met the drinking water target, 95 countries have met the sanitation target and 77 countries have met both; Worldwide, 2.1 billion people have gained access to improved sanitation. The proportion of people practicing open defecation has fallen almost by half since 1990" (Nações Unidas, 2015a, p.7). No entanto, o relatório aponta a permanência de deficiências e desafios que ainda devem ser enfrentados. Sobre a água diz: "Water scarcity affects 40 per cent of people in the world and is projected to increase" (Op. cit., p.8).

${ }^{27}$ Assim, foi decidido o estabelecimento de um processo intergovernamental com vistas a avaliar e aperfeiçoar os ODM, culminando com a aprovação documento Transformando Nosso Mundo: A Agenda 2030 para o Desenvolvimento Sustentável. "A Agenda consiste em uma Declaração, 17 Objetivos de Desenvolvimento Sustentável (ODS) e as 169 metas, uma seção sobre meios de implementação e de parcerias globais, e um arcabouço para acompanhamento e revisão. (...) Os ODS aprovados foram construídos sobre as bases estabelecidas pelos Objetivos de Desenvolvimento do Milênio (ODM), de maneira a completar o trabalho deles e responder a novos desafios. São integrados e indivisíveis, e mesclam, de forma equilibrada, as três dimensões do desenvolvimento sustentável: a econômica, a social e a ambiental.”. Disponível em: <http://www.br.undp.org/content/brazil/pt/home/post-2015.html> Acesso em: 09 mai. 2017. 


\section{ÁGUA: DA LÓGICA DE MERCADO À EFETIVAÇÃO COMO DIREITO HUMANO. UMA LEITURA A PARTIR DO DIREITO INTERNACIONAL DOS DIREITOS HUMANOS}

começo daquela década, que se iniciam questionamentos e são deflagradas oposições, às vezes com contornos dramáticos ${ }^{28}$, sobre a viabilidade dos modelos de gestão privada. $\mathrm{Ou}$ seja, a já mencionada onda de privatizações no setor de abastecimento e saneamento, bem como a proliferação de estruturas de gestão orientadas pelo e para o mercado, mostraram certa ineficácia e incapacidade de resolver o acesso à água e ao saneamento, dificultando a realização plena de direitos conexos.

No começo dos anos 2000, como reflexo deste contexto, o Comitê para os Direitos Econômicos, Sociais e Culturais das Nações Unidas (CDESC), cuja atribuição reside em interpretar o PIDESC, emitiu o Comentário Geral número 15, de 2002. A água e o saneamento básico são então reconhecidos como direitos humanos e abarcam o rol das condições efetivas para o pleno exercício do direito à vida e a uma série de outros direitos correlatos e previstos no PIDESC (arts. $11^{\circ}$ e $12^{\circ}$ ). O Comentário ${ }^{29}$ assinala, em sua introdução: "Water is a limited natural resource and a public good fundamental for life and health. The human right to water is indispensable for leading a life in human dignity. It is a prerequisite for the realization of other human rights" (CDESC, 2002, p. 1).

Finalmente, em 2010, Assembleia das Nações Unidas (AG/ONU) aprovou resolução A/RES/64/292, que reconheceu a água limpa e segura e o saneamento como direito humano essencial para o gozo pleno da vida e de todos os outros direitos (Nações Unidas, 2010, p. 2). A AG/ONU ainda instou os Estados a cooperarem no sentido de implementar e aperfeiçoar políticas que melhorem a acessibilidade à água potável e ao saneamento. Pode-se dizer que este foi um avanço, mas ainda tímido, e, por esta razão, em 2015, a AG/ONU aprovou a resolução A/RES/70/169. Não apenas pelo caráter mais amplo se comparada à anterior, a resolução A/RES/70/169 representou também um ganho de legitimidade política internacional. Se em 2010 não houve unanimidade na votação da AG/ONU (122 a favor, nenhum contra, 41 abstenções e 29 ausentes), em 2015 o conteúdo foi aprovado de forma unânime, não se configurando nenhuma ressalva pelos Estados-membros.

\footnotetext{
${ }^{28}$ Lembre-se, por exemplo, o caso da "guerra da água da Bolívia" ou "guerra da água de Cochabamba". Este evento foi uma revolta popular que ocorreu naquela cidade boliviana no começo de 2000 . O objeto dos protestos era a recusa à privatização do sistema municipal de água e saneamento, já que as tarifas cobradas pela empresa Aguas del Tunari (ligada ao grupo empresarial norte-americano Bechtel) haviam dobrado de valor. Após cerca de quatro meses de protestos violentos, o governo cedeu à pressão popular e desistiu da privatização, sendo o serviço retomado pela prefeitura de Cochabamba (Perreault, 2006).

${ }^{29}$ Comentários Gerais do CDESC não são caracterizados, nos termos do art. 38 do Estatuto da Corte Internacional de Justiça (ECIJ), como direito vinculante. São compreendidos como soft law. Isto significa que as regras tem valor normativo menos constritor do que as normas jurídicas tradicionais. No entanto, do ponto de vista político, tais normas podem ter significativo peso, em razão do reconhecimento da legitimidade política e técnica do órgão que as emite, podendo ser utilizadas subsidiariamente na tarefa interpretativa das normas cogentes (Winkler, p. 38).
} 
Outro aspecto relevante de ser lembrado é que a A/RES/70/169 reconheceu o acesso à água e ao saneamento como direitos conectados, no entanto, distintos. Ambos compõem o direito à condição de vida suficiente a que o PIDESC faz alusão. Mas o processo de negociação entre os Estados trouxe à baila tensões e pressões de ordem política e social, que culminaram naquela distinção. A resolução diz: "that the human rights to safe drinking water and sanitation as components of the right to an adequate standard of living are essential for the full enjoyment of the right to life and all human rights" (Nações Unidas, 2015b, p. 2). E continua: [The General Assembly], Recognizes that the human right to safe drinking water entitles everyone, without discrimination, to have access to sufficient, safe, acceptable, physically accessible and affordable water for personal and domestic use, and that the human right to sanitation entitles everyone, without discrimination, to have physical and affordable access to sanitation, in all spheres of life, that is safe, hygienic, secure, socially and culturally acceptable and that provides privacy and ensures dignity, while reaffirming that both rights are components of the right to an adequate standard of living (Ibidem).

Por fim, a resolução ainda aponta para a importância da cooperação internacional entre vários setores da sociedade, no sentido de viabilizar a melhoria no acesso à água e ao saneamento. Afirma que os Estados têm a responsabilidade primária de assegurar a plena realização de todos os direitos humanos e decide prosseguir o exame da questão em sua $72^{\mathrm{a}}$ sessão, a ser iniciada em setembro de 2017.

\section{CONSIDERAÇÕES FINAIS}

A pesquisa teve caráter prospectivo, no sentido de delimitar a transição no valor jurídico conferido à água, apontando para a complexidade e caráter indubitável da crise ambiental, da qual a escassez e as disputas hídricas são sua faceta talvez mais dramática.

$\mathrm{O}$ acesso à água limpa e em quantidade suficiente representam para o indivíduo um direito básico de garantia de sobrevivência e saúde, em que manifesta o vínculo entre meio ambiente e os direitos humanos. Ele "está demonstrado pelo fato de que, ocorrendo degradação ambiental, podem ser agravadas violações aos direitos humanos, e, por outro lado, as violações de direitos humanos podem levar à degradação ambiental ou tornar mais difícil a proteção do meio ambiente. Tais situações ressaltam a necessidade de fortalecer o desenvolvimento do direito à alimentação, à água e à saúde", sendo a normatividade jurídica uma via para tal [grifo nosso] (Guerra, 2016, p. 380). 
A guinada para uma visão da água como recurso econômico coloca um enorme desafio, pois pode ensejar mais exclusão e a não-efetivação do direito à vida, bem como a uma série de outros direitos humanos em condições plenas. Assim, os recentes avanços no sistema internacional de proteção ao direito humano à água, tratando-o como um campo relativamente autônomo em relação ao direito humano ao saneamento básico, representam importante evolução jurídica e política. Este encaminhamento, reflexo progressivo e ainda em construção da ideia da água como direito humano, foi dado pela resolução A/RES/70/169. Mas esta discussão ainda está aberta e certamente será recolocada no futuro.

Nesse sentido, A/RES/70/169 deve ser celebrada e estimamos que a efetiva proteção da água, a ser garantido para as presentes e futuras gerações, seja a construção política de esforços que desemboquem na elaboração de vários tratados internacionais em prol do reconhecimento da água como direito humano, não apenas como mera declaração, mas que essas normas sirvam para fortalecer e, sobretudo, garantir a água como direito humano para todos de forma indiscriminada.

\section{REFERÊNCIAS BIBLIOGRÁFICAS}

BARLOW, M. y CLARKE, T. Oro Azul. Las multinacionales y el robo organizado de agua en el mundo. Barcelona, Paidós Controversias. 2004.

BARRAQUÉ, B. La politique européenne dans le domaine de l'eau: impact, implication, impératifs. Rev. Française de Géoéconomie. 1998/4: 125-136.

. Pour une histoire des services d'eau et d'assainissement en Europe et en Amérique du Nord. Flux. (N 97-98) 2014/3 p.4-15

CARRERA-FERNANDEZ, J. e GARRIDO, R.J. Economia dos Recursos Hídricos. Salvador, EDUFBA. 2002.

CLARKE, M. Regulation: the Social Control of Business between Law and Politics. London. MacMillan Press. 2000.

COCKLIN, C. \& BLUNDEN, G. Sustainability, Water Resources and Regulation. Geoforum, 1998/29 (1): 51-68.

CDESC - Comitê para os Direitos Econômicos, Sociais e Culturais da Organização das Nações Unidas. Comentário Geral no 15. 2002. Disponível em: <http://www2.ohchr.org/english/issues/water/docs/CESCR_GC_15.pdf>. Acesso em: 09 de maio de 2017.

GARCÍA, A. El Derecho Humano al Agua. Madrid, Editorial Trotta, 2008.

GUERRA, S. Direitos humanos: curso elementar. 4.ed. São Paulo: Saraiva, 2016. 
Curso de Direito Ambiental. 2. ed. São Paulo: Atlas, 2014.

Crise Ecológica na Sociedade de Risco. Revista de Direito da Cidade (Uerj), v. 5, n. 2, p. 77-105, 2013.

Direito Internacional Ambiental. Rio de Janeiro: Freitas Bastos, 2006.

. Direito internacional dos direitos humanos. 2. ed. São Paulo: Saraiva,

2015.

HOBBS, G. J. Historical Perspective on Western Land and Water Law. Paper presented at the Colorado River Compact Symposium, Santa Fe, New Mexico. Processed, 1997.

MAJONE, G. (ed). Deregulation or Reregulation? Regulatory reform in Europe and United States. London: Pinter Publishers. 1990.

MATTOS, P. T. L. Regulação econômica e democracia: contexto e perspectivas na compreensão das agências de regulação no Brasil. In: FARIA, J. E. Regulação, Direito e Democracia. São Paulo: Ed. Fundação Perseu Abramo, pp. 43-66. 2002.

MCCRAW, T. K. Prophets of Regulation. Cambridge, Massachusetts, Harvard University Press. 1984.

MORAN, M. e PROSSER, T. Introduction: Politics, Privatization and Constitutions. In: Moran, M.; Prosser, T. (eds.), Privatization and Regulatory Change in Europe. Buckingham: Open University Press. 1994.

MOURA, M. G. Agências regulatórias no Brasil: os casos dos setores de telecomunicações, eletricidade e petróleo/gás natural. Revista do Serviço Público, Brasília, ano 53, nº 2, jun-mar. 2002.

MOURA, V. P. Gestão de Recursos Hídricos na Bacia do rio Paraíba do Sul: experiências e desafios da cobrança pelo uso da água. Dissertação de Mestrado (Mestrado em Geografia). Programa de Pós-graduação em Geografia da Universidade Federal do Rio de Janeiro (PPGG/UFRJ). Depto. de Geografia - Instituto de Geociências/UFRJ. 2006. 178p.

NAÇÕES UNIDAS. UN World Water Development Report 2017. Disponível em: <http://www.unwater.org/publications/publications-detail/en/c/853650/>. Acesso em: 10 mai. 2017.

The Millennium Development Goals Report 2015. 2015a. Disponível em: <http://www.un.org/millenniumgoals/2015_MDG_Report/pdf/MDG\%202015\%20rev\%20(Jul y\%201).pdf >. Acesso em: 08 mai. 2017.

The human rights to safe drinking water and sanitation. $2015 \mathrm{~b}$. Resolution adopted by the General Assembly on 17 December 2015. A/RES/70/169. Disponível em: <http://www.un.org/en/ga/70/resolutions.shtml> Acesso em: 14 mai. 2017.

Rev. de Direitos Humanos em Perspectiva | e-ISSN: 2526-0197| Brasília | v. 3 | n. 1 | p. 81 - 102 | Jan/Jun. 2017 
The human right to water and sanitation. Resolution adopted by the

General Assembly on 28 July 2010. 2010. A/RES/64/292. Disponível em: < http://www.un.org/en/ga/64/resolutions.shtml > Acesso em: 14 mai. 2017.

The future we want. 2012. Disponível em: <http://www.un.org/disabilities/documents/rio20_outcome_document_complete.pdf.> Acesso em: 08 mai. 2017.

The Dublin Statement on Water and Sustainable Development. 1992a.

Disponível em: <http://www.un-documents.net/h2o-dub.htm> Acesso em: 08 mai. 2017.

Conferência das Nações Unidas sobre Meio Ambiente e Desenvolvimento. 1992b. Disponível <http://www.onu.org.br/rio20/img/2012/01/rio92.pdf〉 . Acesso em: 08 mai. 2017.

Agenda 21. 1992c. Disponível <http://www.onu.org.br/rio20/img/2012/01/agenda21.pdf〉. Acesso em: 08 mai. 2017.

Report of the United Nations Water Conference Mar de Plata, 14-25 March 1977. Disponível em: <http://repository.un.org/handle/11176/202085>. Acesso em: 08 mai. 2017.

ORGANIZAÇÃO MUNDIAL DA SAÚDE - OMS. Aluminium in drinking-water. 2010. Disponível em <http://www.who.int/water_sanitation_health/publications/en/>. Acesso em 06 de maio de 2017.

Antimicrobial resistance: an emerging water, sanitation and hygiene issue. 2015. Disponível em <http://www.who.int/water_sanitation_health/publications/en/>. Acesso em 06 de maio de 2017.

Guidelines for drinking-water quality. 2011. Disponível em <http://www.who.int/water_sanitation_health/publications/en/>. Acesso em 06 de maio de 2017.

PERREAUlT, T. From the Guerra Del Agua to the Guerra Del Gas: Resource Governance, Neoliberalism and Popular Protest in Bolivia. Antipode. 150-172. 2006.

PORTO-GONÇALVES, C. W.. El agua no se niega a nadie - la necesidad de escuchar otras voces. Polis (Santiago), v. 5, p. 39-69. 2006.

QUIRICO, O. e BOUMGHAR, M. (Ed.). Climate Change and Human Rights. An International and Comparative Law Perspective. Nova Iorque: Routledge, 2016.

RIBEIRO, W. C. Geografia Política da Água. Editora Annablume, São Paulo, 2008.

SALETH, R.M. e DINAR, A. Institutional Changes in Global Water Sector: trends, patterns, and implications. Water Policy, 2. pp. 175-199. 2000.

SATOKO, K. et al. Veio para ficar: a remunicipalização da água como uma tendência global. Unidade Internacional de Pesquisa de Serviços Públicos (PSIRU). 2015. Disponível 
em https://www.tni.org/sites/www.tni.org/files/download/heretostay-pt.pdf. Acesso em 25 de abril de 2017.

SHIVA, V. La Guerre de L'eau: Privatisation, Pollution et Profit. Paris. Parangon. 2003.

SIMPSON, L. W e RINGSKOG, K. Water Markets in the Americas. Directions in Development. World Bank, Washington D. C. 1997.

WINKLER, I. T. The Human Right to Water: Significance, Legal Status and Implications for Water Allocation. Oregon: Hart Publishing, 2012. 